\title{
Pain and satisfaction: the case of isolated COVID-19 patients of Pakistan
}

\author{
Wajiha Haq ${ }^{\text {Corresp., } 1}$, Siddrah Irfan ${ }^{2}$, Syed Hassan Raza ${ }^{3}$, Waqar Ahmed $^{4}$, Mian Alam ${ }^{5}$, Samia Wasif ${ }^{6}$, Muhammad \\ Wasif Malik $^{7}$, Saeed Ahmad ${ }^{8}$ \\ ${ }^{1}$ School of Social Sciences and Humanities, National University of Sciences and Technology, Islamabad, Punjab, Pakistan \\ Department of Behavioral Sciences, National University of Sciences and Technology, Islamabad, Pakistan \\ 3 School of Economics, Quaid-i-Azam University, Islamabad, Pakistan \\ 4 District Health Authority, Rawalpindi, Pakistan \\ ${ }^{5}$ Corona Management Centre, Rawalpindi Institute of Urology \& Transplantation, Rawalpindi, Pakistan \\ 6 Department of Humanities, COMSATS University, Islamabad, Pakistan \\ 7 Field Epidemiology \& Disease Surveillance Division, National Institute of Health, Islamabad, Pakistan \\ 8 Public Health England, Islamabad, Pakistan \\ Corresponding Author: Wajiha Haq \\ Email address: dr.wajihahaq@s3h.nust.edu.pk
}

\section{Background}

Over 3 million people lost their lives across the globe due to the COVID-19 related pandemic. The unprecedented restrictions on mobility have imposed in the form of isolation, quarantines, and lockdowns to curb the profound effects of the pandemic and retain physical health. This study examined the relationship between various pain levels, demographic variables and patient satisfaction with COVID-19 during isolation.

\section{Methods}

The primary data in this study were collected from isolated patients during their isolation and treatment in a public hospital. We obtained information from patients with COVID-19 $(\mathrm{N}=100)$ about their demographic characteristics, varying levels of pain, and satisfaction with the services provided during the isolation period. We computed the descriptive statistics to explain the profile of participants, ANOVA was used to find out the difference between various groups on patient satisfaction, and structural equation modeling was performed to examine the link between pain levels, demographic factors, and patient satisfaction. This analysis was performed with STATA and SmartPLS-3.

\section{Results}

The findings of this study ascertained that respondent's education (Beta, $\beta=2.961, p=0.003$ ), assets such as possession of a house $(\beta=4.563, p=0.000)$, perception of income adequacy during the lockdown $(=2.299, p=0.022)$, and negligence in prevention $(\beta=1.975, p=0.049)$ significantly affects patient satisfaction during the isolation period. Moreover, satisfaction with life, physicians and medicine, income adequacy, and fear of the participants was significantly linked to the pain level (Model F-stat=86.323, $p=0.0001)$. Patients who were satisfied with their treatment had significantly lower odds of having pain (OR 0.023, 95\% Cl: 0.001-0.0452). Patients who had enough income to meet their basic necessities were found to have significantly lower odds of having pain (OR $0.155,95 \% \mathrm{Cl}: 0.032-0.740$. 


\section{Discussion and Conclusion}

We conclude that a higher level of education, low income, and living in a rented house contributes significantly to the feeling of more satisfaction with the provided services. This implies that people with more affluent backgrounds are less likely to be satisfied with the provided services as low-income and living in rented house groups are more satisfied during isolation than others. The pain level is also affected by subjective factors such as fear and satisfaction which need to be considered while doing patient management. This study can be helpful in improving the delivery of public services of isolation centers by considering various characteristics and demographic factors of patients. 


\section{Pain and satisfaction: the case of isolated COVID-19 patients of}

\section{Pakistan}

3 Wajiha Haq ${ }^{1 *}$, Siddrah Irfan ${ }^{2}$, Syed Hassan Raza ${ }^{3}$, Waqar Ahmed ${ }^{4}$, Mian Awais Alam ${ }^{5}$, Samia

4 Wasif $^{6}$, Muhammad Wasif Malik ${ }^{7}$, Saeed Ahmad ${ }^{8}$

5

$6{ }^{1}$ School of Social Sciences and Humanities, National University of Sciences and Technology,

7 Islamabad, Pakistan

$8{ }^{2}$ Department of Behavioral Sciences, School of Social Sciences and Humanities, National

9 University of Sciences and Technology, Islamabad, Pakistan

$10{ }^{3}$ School of Economics, Quaid-i-Azam University, Islamabad, Pakistan

$11{ }^{4}$ District Health Authority, Rawalpindi, Pakistan

$12{ }^{5}$ Corona Management Centre, Rawalpindi Institute of Urology \& Transplantation, Rawalpindi,

13 Pakistan

$14{ }^{6}$ Department of Humanities, COMSATS University, Islamabad, Pakistan

$15{ }^{7}$ Field Epidemiology \& Disease Surveillance Division, National Institute of Health, Islamabad,

16 Pakistan

$17{ }^{8}$ Public Health England, Islamabad, Pakistan

18

*Corresponding author

Wajiha Haq, $\mathrm{PhD}$

21 National University of Science and Technology,

22 School of Social Sciences and Humanities, H-12, Islamabad, Pakistan

23 Email address: dr.wajihahaq@s3h.nust.edu.pk

\section{Abstract}

\section{Background}

Over 3 million people lost their lives across the globe due to the COVID-19 related pandemic.

The unprecedented restrictions on mobility have imposed in the form of isolation, quarantines, and lockdowns to curb the profound effects of the pandemic and retain physical health. This study examined the relationship between various pain levels, demographic variables and patient satisfaction with COVID-19 during isolation.

\section{Methods}

34 The primary data in this study were collected from isolated patients during their isolation and treatment in a public hospital. We obtained information from patients with COVID-19 (N=100) about their demographic characteristics, varying levels of pain, and satisfaction with the services 
38 of participants, ANOVA was used to find out the difference between various groups on patient 39 satisfaction, and structural equation modeling was performed to examine the link between pain 40 levels, demographic factors, and patient satisfaction. This analysis was performed with STATA 41 and SmartPLS-3.

\section{Results}

43 The findings of this study ascertained that respondent's education (Beta, $\beta=2.961, p=0.003$ ), assets 44 such as possession of a house $(\beta=4.563, \mathrm{p}=0.000)$, perception of income adequacy during the 45 lockdown $(=2.299, \mathrm{p}=0.022)$, and negligence in prevention $(\beta=1.975, \mathrm{p}=0.049)$ significantly 46 affects patient satisfaction during the isolation period. Moreover, satisfaction with life, physicians 47 and medicine, income adequacy, and fear of the participants was significantly linked to the pain 48 level (Model F-stat=86.323, $\mathrm{p}=0.0001$ ). Patients who were satisfied with their treatment had 49 significantly lower odds of having pain (OR 0.023, 95\% CI: 0.001-0.0452). Patients who had 50 enough income to meet their basic necessities were found to have significantly lower odds of 51 having pain (OR 0.155, 95\% CI: 0.032-0.740.

\section{Discussion and Conclusion}

53 We conclude that a higher level of education, low income, and living in a rented house contributes 54 significantly to the feeling of more satisfaction with the provided services. This implies that people

55

61 with more affluent backgrounds are less likely to be satisfied with the provided services as lowincome and living in rented house groups are more satisfied during isolation than others.

The pain level is also affected by subjective factors such as fear and satisfaction which need to be considered while doing patient management. This study can be helpful in improving the delivery of public services of isolation centers by considering various characteristics and demographic factors of patients.

Keywords: COVID-19; isolation; satisfaction; fear; pain

\section{Introduction}

The COVID-19 pandemic has jolted the whole world. The outbreak started in China in late 2019 and turned into a pandemic due to its highly transmittable nature (Lu, Liu, \& Jia, 2020). In Pakistan, until October 18, 2020, 323,019 persons contracted the disease, whereas 6,654 persons died due to COVID-19 (Ministry of National Institute of Health, 2020). However, mRNA vaccines 
69 are fully developed to combat the severe consequences of COVID-19 by producing antibodies to 70 combat the disease. The longevity of antibodies and their effectiveness against different variants 71 of the virus remains a mystery. The most effective method to reduce the viral spread of highly 72 transmittable diseases has been community-wide containment through quarantines and isolations 73 (Prevention, 2020). The practice of timely quarantine and isolation during previous outbreaks has 74 shown results curtailing the spread of the disease (Giubilini, Douglas, Maslen, \& Savulescu, 2018). 75 It is often argued that quarantine and isolation are two sides of the same coin, but there are two 76 folds of dissimilarity in terms of definition. Quarantine means isolating the persons who have 77 been potentially exposed to the virus and are not sick yet to observe the virus's symptoms and 78 79 80 reduce the potential spread of the disease. On the contrary, isolation is the separation of confirmed infected patients (Brooks et al., 2020). The incubation period of the virus is 1-14 days (Organization, 2020). This created worry for the public about the isolation and management of isolation. Therefore, quarantine and isolation facilities are established across the world. In

82 Pakistan, hundreds of places converted into temporary quarantine centers to facilitate quarantine 83 and in hospitals, separate isolation wards were made for COVID-19 patients.

84 Quarantines and isolations of patients have played a vital role in controlling the spread of the 85 disease. On the one hand, they facilitate in reducing the infection, but, on the other, cause many 86 side effects, which is recently argued as shadow pandemic. The psychological side effects of 87 isolation include anger, depression, anxiety, loss of patient satisfaction and mental wellbeing, and 88 loss of self-control (Abad, Fearday, \& Safdar, 2010; Rees, Davies, Birchall, \& Price, 2000). 89 Quarantine is also known to create a cardiovascular risk due to social isolation and depression 90 (Mattioli, Puviani, Nasi, \& Farinetti, 2020). Due to the known effects of isolation, it is deemed 91 important to investigate the socio-psychological effects of isolation on COVID-19 patients. Thus, 92 the isolation experience can be improved so that the positive effects dominate the negative side 93 effects. These negative psychological effects also hinder the care and treatment of the patient by 94 creating an overall negative impact on the patient's mind and body.

95 Developing countries are already struggling with the scarce health facilities and services to combat 96 the disease. Where a patient in isolation experiences fear, anxiety, and depression (Maunder et al., 97 2003). Due to limited resources, a negative experience of the isolation wards can add to the 98 discouragement of people to come to hospitals for recovery and may also cripple their belief in the 99 health system of the country. Past studies provide evidence that pain management practices 
100 improve the health of a patient (including patients with chronic diseases) experience (Amol Soin 101 et al., 2020; Anthony Jnr, 2021a) and innovative methods such as digital care can be helpful during 102 pandemic (Anthony Jnr, 2021b), but the COVID-19 may lead to aggravated perceived pain of 103 individuals (Song et al., 2020). The negative experience is quite evident during isolation. 104 Therefore, there is a need to investigate the factors that may help improve the isolation experience 105 of patients and factors that, if controlled, can reduce the perceived pain of the patients of COVID106 19. Additionally, the need is to investigate the experience of COVID-19 patients so that their 107 experience can be improved in the future and pain can be mitigated. Factually, reduction in pain 108 improves patient satisfaction (Baker, Van der Meulen, Lewsey, \& Gregg, 2007; Scher, Meador,

109

110

111

112

113

114

115

116

117

118

119

120

121

122

123

124

125

126

127

128

129

130 Van Cleave, \& Reid, 2018). To address this research question, we focused on the experiences of the patients isolated in the COVID-19 ward. We hypothesized that patient's satisfaction during isolation might differ according to the distinct demographics of the patient. Besides, it may also be affected by different levels of pain and other factors. Whereas fear and other factors may affect the pain levels (Asmundson, Vlaeyen, Vlaeyen, \& Crombez, 2004; Keefe, Abernethy, \& C. Campbell, 2005). Secondly, we focused on investigating the difference in patient satisfaction of COVID-19 patients with distinct demographics. Later, we investigated the effect of different factors on isolation, pain level, and patient satisfaction in separate models. The specific research questions are:

- Does patient's satisfaction during COVID-19 isolation differ among demographic groups.

- What are the factors affecting the pain level (subjective) of the COVID-19 patient during isolation?

- What are the factors affecting patient's satisfaction during COVID-19 isolation?

The introduction section is followed by materials and methods, explaining data collection, sample, and data analysis technique. The third section includes descriptive statistics, patient satisfaction among patients, factors affecting pain level, and factors affecting patient satisfaction. Results are followed by discussion and conclusion.

\section{Materials \& Methods}

This study relies on primary data collection for making inferences. We conducted a cross-sectional survey to collect the information from the COVID-19 patients who were isolated in the government centers. The study focused on the investigation of patient satisfaction and their pain 
131 perception of isolated patients. The variable of fear comprises of 7 dimensions. The questionnaire 132 adopted the fear scale from the study conducted by Ahorsu et al. (2020). The pain level was 133 measured using 5 point measurement scale based on literature (Huskisson, 1974). Patient 134 satisfaction is based on the scale based on Likert type scale. The questionnaire was developed 135 based on literature (Abad et al., 2010; Rees et al., 2000; Tang et al., 2020) and was validated by 136 experts, hospital management, and people working in isolation wards with COVID-19 patients. 137 Patient satisfaction has been operationally defined in this study as the satisfaction of COVID-19 138 patients with the services provided in the public isolation center. Patient satisfaction is measured 139 by asking questions about satisfaction with overall services, nurses, doctors, medicine, food, 140 cleanliness, and behavior of peer patients. The Cronbach alpha for the patient satisfaction scale for 141 the current study is excellent (i.e., 0.93), and the fear of covid scale is moderate (0.61). The 142 benchmark of Cronbach alpha is according to the literature (Taber, 2018)). Since we measure pain 143 through one item, Cronbach alpha was not calculated for this item (Bland \& Altman, 1997).

\section{Data collection}

145 The sample was collected from COVID-19 patients who were isolated in COVID-19 isolation 146 wards. The sample data was collected from the patients during their isolation using purposive 147 sampling. Purposive sampling is a selective sampling where the population with certain characteristic is selected. Based on the objective of the study, only the COVID-19 patients were purposively selected for the study. However, at next stage, the COVID-19 patients to be included in the sample were selected randomly (for more details on purposive sampling, see Tongco (2007)). Due to the highly transmittable nature of the virus, it was very difficult to get permission to access isolated patients. The isolated patients did not have their digital gadgets as well. With the help of paramedic staff, the data were collected from patients during their isolation to avoid the forgetting bias in reporting their responses. The paramedic staff who helped in the collection of the data was first trained to collect the data. Due to reservations imposed by the nature of the disease, we could only access the patients of one hospital in Rawalpindi. Rawalpindi Institute of Urology and Transplantation hospital has one of the largest isolation centers in Pakistan with 50 designated beds for COVID-19 patients and is equipped with the necessary equipment, including ventilators. The hospital gave ethical clearance for conducting the research (Ethical approval Letter Ref No. 201). No one could go into isolation wards except for the staff. The staff working in 
162 to get the questionnaires filled from the patients. The data were collected during June-August 2020

163 in Rawalpindi when COVID-19 was at its peak. Patients were briefed about the purpose of the 164 research, confidentiality of the responses and right to withdraw at any time during the research.

165 Patients participated in the research with their voluntary consent knowing the purpose of the 166 research. A separate written consent was not taken; however, verbal permission was taken by 167 asking their willingness to give the data and filling out the questionnaire showed their informed 168 consent. The questionnaire stipulated the purpose of the research and assured anonymity. In 169 addition, the questions, revealing their identity were not asked.

\section{Sample}

171 The sample size for this study was calculated through G-power software by selecting parameters 172 including the effect size, which was 0.15 , error probability being 0.05 , power as 0.95 , and a total 173 number of predictors were 5. The required calculated sample required was 107. However, a 174 questionnaire booklet was distributed among 110 participants. Among them, six refused to 175 participate, and four booklets were 90 percent incomplete, so their responses were discarded. The 176 response rate was $90.9 \%$. Therefore, the final analysis was done on 100 participant's responses.

\section{Data Analysis Technique}

178 Two software, including STATA and SmartPLS-3, were used to test the hypotheses of this study. 179 Smart PLS is software for variance-based structural equation modeling (SEM) using the partial 180 least squares (PLS) path modeling method. The benefits of the PLS approach consist of 181 measurement settings, theoretical settings, practical attention, and distributional attentions (Falk $182 \&$ Miller, 1992). The PLS approach relies on the data and is an exploratory methodology. For the 183 present study, SmartPLS was beneficial due to its prediction-oriented approach and did not need 184 large sample sizes (Chin \& Newsted, 1999). Moreover, PLS is used to determine the latent 185 variables. Chin and Newsted (1999) stated that the PLS approach uses a weighted sum of indicators 186 for creating component scores of latent variables. Normality was checked through skewness and 187 kurtosis through Statistical Package for the Social Sciences (SPSS). Results showed that data were 188 normally distributed for all the variables as the values of skewness and kurtosis were found to be 189 in in the acceptable range (skeweness: \pm 2 , kurtosis: \pm 3) between 0.005-2.203 and no 190 multicollinearity among variables was observed. Furthermore, a one-way analysis of variation 191 (ANOVA) was used to test for the differences in patient satisfaction across the categories of 192 training levels and marital condition. 
193 To analyze various factors affecting the level of pain, an ordered logistical regression was used.

194 Due to the orderly nature of the responses of the pain variable, that technique was chosen.

195 The general model of ordered logistic regression is:

196

$$
\operatorname{Prob}\left(y_{i}=\mathrm{j}\right)=\mathrm{B}\left(z_{j+1}-X_{i} \varnothing\right)-\mathrm{B}\left(z_{j}-X_{i} \emptyset\right)
$$

197 Substituting the value of B

198

$$
\operatorname{Prob}\left(y_{i}=\mathrm{j}\right)=\frac{\exp \left(z_{j+1}-X_{i} \emptyset\right)}{1+\exp \left(z_{j+1}-X_{i} \emptyset\right)}-\frac{\exp \left(z_{j}-X_{i} \emptyset\right)}{1+\exp \left(z_{j}-X_{i} \varnothing\right)}
$$

199

200

201

202

203

204

205

206

207

208

209

210

211

212

213

214

215

216

217 relations.

\section{Results}

219 Descriptive statistics

220

221

As illustrated in Table 1, the mean age of the sample is 38 years, ranging between 19 and 76 years.

222

where " $\mathrm{i}$ " is the number of observations. " $\mathrm{j}$ " is $1, \ldots, 5$ and represent the values for $y$. " $\mathrm{X}$ " is the vector of independent variables, " $\varnothing$ " is the coefficient vector and $z_{j}$ are the cut points of the distribution. The independent variables include fear, age, satisfaction with medicine during isolation, sufficiency of income, satisfaction with life and satisfaction with the doctors.

Structural equation modeling was applied to see the relationship of factors with patient satisfaction. For the analyzing patient satisfaction, structural equation modelling (SEM) was used. The underlying model of SEM is linear model. The general linear model in vector form is given below:

$$
y_{i}=y_{i} \Omega+\mu
$$

where " $y_{i}$ " is a vector of outcome variable and " $\Omega$ " is a matrix of parameters constrained according to the association of variables. The independent variables for the pain satisfaction model are age, number of dependants, household size, education, house ownership, marital status, income adequacy, negligence and pain level. PLS software was used because it provided reliable results even with a small sample size and is suitable for predicting. Following Hair et al., (2013) criteria, the structural model has been assessed via bootstrapping procedure by looking at the values of beta, R-square, and corresponding t-values in the research model among latent constructs. In addition, Hair and colleagues (2013) have also suggested ways of determining effect size (fsquare). The predictive power of the research model was determined by the R-square value of the dependent variable, while the trajectory coefficients assess the strength of the hypothetical Most COVID-19 patients were homeowners and heads of families. Most of the respondents reported that they were happy before the eruption of the COVID-19 pandemic. In addition, most 
223 of the participants who remained in an isolation center were graduates $(n=31)$ or postdoctoral $224(\mathrm{n}=23)$ in full-time employment $(\mathrm{n}=62)$.

\section{Patient satisfaction among patients}

226 Patient satisfaction is the perception of medical facilities and paramedic care (Lochman, 1983).

227 We have tested whether patient satisfaction is different among the different levels of education, 228 marital status, and gender. To achieve the objective, ANOVA is used, and the results are shown in 229 Table 2. The first hypothesis is not supported for this data, which implies that quarantine 230 satisfaction is similar across all variable categories. Overall, the mean values indicate that non231 married persons are more satisfied with the isolation facility than married, widowed or divorced 232 persons, but the difference in patient satisfaction across categories is not significant. On the other 233 hand, those who have done graduation reported high-level satisfaction compared to those who 234 have primary, secondary, or college-level education, and the difference between the categories is 235 not significant. Furthermore, there is no difference in mean score in levels of satisfaction between 236 females and males, which is in agreement with the literature where patient satisfaction is found to 237 not vary with demographics (Karaca \& Durna, 2019). Hence, from these results, it is evident that 238 patient satisfaction does not vary in people with different demographics, keeping other things 239 constant, which raises the need to investigate other factors apart from medical care that may affect 240 patient satisfaction and may eventually improve the experience of patient satisfaction the COVID24119 patients.

242 In the next section, we will see the factors affecting the pain level, whereas pain and other factors 243 also affect the patient satisfaction of individuals.

\section{Factors affecting Pain Level}

245 The level of pain is a subjective phenomenon and therefore affected by subjective factors beyond 246 objective reasons. We examined the effect of fear and other factors on the level of pain and 247 attempted to model the subjective component of pain. The respondents were asked about the pain 248 level on a five-point scale ranging from no pain to unspeakable. The results have been analyzed 249 using ordered logistic regression and shown in Table 3. Based on literature, the variables were 250 identified. The significance of the variables is analyzed through t-test and the model through F251 test. The robustness of the model is checked through adding and dropping of variables and the 252 final model was selected based on Akaike Information Criteria (AIC) and Bayesian Information 253 Criteria (BIC). The AIC and BIC criteria suggests Model 1 as the final model and is significant 
254 which is tested through F-test. According to the findings, when the respondent is neutral with 255 respect to fear rather than disagreeing, there is a higher probability of having a higher level of pain. 256 This suggests that patients being neutral about fear raises the likelihood of having a higher level 257 of pain. In addition, as satisfaction with the medication supplied in the isolation facility increases, 258 the probability of experiencing pain decreases. This indicates that if a person is satisfied with the 259 treatment, then the sensing of pain will also be less as the patent will be anticipating to get better 260 before long. The probability of having higher pain reduces if a person can afford some necessities 261 compared to the situation where the income is not adequate. Income adequacy suggests the 262 affordability of treatment and better, treatment may reduce pain and pain perception. An interesting 263 result came out of the data, suggesting that patients with COVID-19 who are more satisfied with 264 their lives are more likely to have more pain. People having contended life are more likely to report 265 a higher level of pain subjectively. COVID-19 is known to be lethal. People with higher life 266 satisfaction might fear the loss of life, and thus these emotions might interpret as higher pain. If 267 the COVID-19 patients are neutral about satisfaction with the doctors as compared to disagreeing, 268 the probability of perceiving higher pain is lower.

\section{Factors affecting patient satisfaction}

270 Based on the literature, the pain level, and other demographic variable factors, significantly affect 271 patient satisfaction. Results indicated that the model fits the data (SRMR=0.049, Chi 272 square $=182.36, \mathrm{NFI}=0.812$ ). Bootstrapping is used to test this hypothesis. Results in Table 4 show 273 that age, education level, house possession, income adequacy during the lockdown, negligence in 274 preventing from corona, and levels of pain have a significant direct effect on patient satisfaction 275 in public isolation centers.

276 The results indicate that patient satisfaction decreases with the increase in age. It was found that 277 people with higher education were more satisfied with the isolation facilities. With the increase in 278 the level of education, awareness can increase, and so the realization of the efforts of doctors and 279 staff and the facilities provided make people more satisfied. Furthermore, people possessing their 280 own home have lower satisfaction from isolation centers than people living in a rental home. 281 People feel better about isolating themselves at home. In addition to this, the results illustrated that 282 those individuals who had enough income to meet their expenses during lockdown reported a low 283 level of satisfaction while having inadequate money increase isolation centers' satisfaction. Those 284 who perceived that they were suffering from COVID-19 due to their negligence displayed a high 
285 level of satisfaction. Neglect has been operationally defined as the carelessness in taking steps to 286 protect themselves from COVID-19. People whose income is adequate are less satisfied with 287 patients. Similarly, having a high level of pain enhances the level of satisfaction at the isolation 288 center. They feel satisfied when they get medical facilities and other services in public isolation 289 centers, which otherwise was not possible at home while facing a high level of pain. On the other 290 hand, several dependents, household size, and marital status are not significantly related to the 291 satisfaction of isolation centers. As a result, the second assumption is partially supported. Table 4 292 shows the t-values, standardized path/ beta coefficients, and outcomes. Overall, the bootstrap 293 analysis indicated that demographic variables added to the model explained $30.4 \%$ of the variance 294 in quarantine satisfaction.

\section{Discussion}

296 The COVID-19 pandemic has jolted the whole world with infectious disease by spreading the 297 sickness and causing mortalities. According to WHO guidance, quarantine and isolation are among 298 the primary methods to reduce the spread of the disease. The literature has shown that isolation 299 may have negative effects on the patients (Mattioli et al., 2020), so it is very important to improve patients' experience by providing them a better environment to recover quickly.

301 Pain is a subjective experience (Koyama, McHaffie, Laurienti, \& Coghill, 2005; Raja et al., 2020).

302 The subjective factors affecting pain are fear, satisfaction with life, income adequacy, satisfaction 303 with doctors and medicine. The age also affects the pain level, but the effect size is very low as 304 the odds are close to 1. The literature says that pain might be due to fear (Crombez, Viane, 305 Eccleston, Devulder, \& Goubert, 2013; Markfelder \& Pauli, 2020). Fear of pain aggravates the 306 feeling of pain (Crombez et al., 2013), and this study found the same on COVID-19 patients. The 307 satisfaction with the doctors and medicine decreases the perception of pain as the person trusts the quality of care given. Similarly, income adequacy brings the affordability of the treatment and less worry about the finances, and hence, perceived income adequacy affects the pain (Crombez et al., 2013). Compared to those who strongly disagree, if a person demonstrates that they are satisfied with their life, the likelihood of experiencing greater pain is high. The individual's satisfaction corresponds to his overall cognitive assessment of life (Bergefurt et al., 2019). Literature reported 313 that more social people tend to report higher satisfaction, happiness (McCarthy \& Habib, 2018). 314 Loneliness not only affects life satisfaction, but also affects health (Bergefurt et al., 2019; Hwang, 315 Rabheru, Peisah, Reichman, \& Ikeda, 2020). The isolated patients having higher life satisfaction 
316 face amplified effects of isolation in terms of emotional and health, wellbeing, which is translated 317 into reporting a higher level of pain.

318 Sprang and Silman (2013) found that individuals in isolation had more post-traumatic disorders 319 than those who were not in isolation. Based on the primary data collected from the COVID-19 320 patients, we found that their satisfaction was not significantly different among people with varying 321 education, gender, and marital status. Outcomes are consistent with patient satisfaction literature. 322 An estimated $40 \%$ of people are satisfied with the isolation facility. Patient satisfaction is affected 323 by income adequacy, house ownership, age, education, negligence, and pain level. Age has a direct 324 effect on patient satisfaction. Patient satisfaction was low among younger patients, as it was not 325 frequent that they were ill or hospitalized. People with adequate income tend to have better health 326 and expect to get high-quality care, and in case there is a discrepancy in the car, they get more 327 dissatisfied than those who do not have a higher financial status. People who do not have adequate 328 income are already negligent of health and health care and do not perceive higher dissatisfaction 329 (Karaca \& Durna, 2019). Education gives awareness and the ability to cope with the disease and 330 positively relates to patient overall satisfaction (Dzomeku, Ba-Etilayoo, Perekuu, \& Mantey, 2013; 331 Wudu, 2021). Negligence in taking preventive measures for COVID-19 has an important effect 332 on patient satisfaction. Highly negligent people taking preventive steps to protect themselves from 333 COVID-19 have higher patient satisfaction as the medical facilities and services make them feel 334 in a safe environment that they were missed in the first place. Patient satisfaction is extremely 335 important for hospital patient satisfaction literature proves that people with a lower perception of 336 quality care tend to complain more about the hospital (Stelfox, Bates, \& Redelmeier, 2004).

337 This study has far-reaching implications for the health care system and patients. The healthcare 338 system needs to improve their isolation facilities though struggling with scarce resources. It will 339 help them to reduce the pain level of patients and improve their experience. With closed borders 340 and a ban on foreign travel, local treatment is the only option for COVID-19 patients. The 341 improved isolation experience will help patients to spread good word of mouth, which will help 342 regain the nation's trust in doctors, paramedic staff, and the health care system despite having 343 scarce resources. This will also help them ensure that the best is being provided to them. They will 344 eventually enjoy the isolation experience, which will not help them recover, but their safe isolation 345 will also protect others from the spread of the disease. Other countries can also derive lessons from 
346 this study by focusing on the factors identified to improve isolated patients' experience in isolation 347 centers.

348 The data collection from isolated COVID-19 patients during isolation was a big hurdle. We did 349 not want to ask patients about their experience after isolation to avoid the bias of forgetting 350 affecting our results. Due to the stated hurdle of access to patients isolated in centers, we could not 351 collect large data. Further research can be done with a large data sample and in different countries 352 to investigate individuals' isolation experience and see the country-specific factors.

353

\section{Conclusions}

355 The novelty of COVID-19 has not only brought issues in the disease treatment and management, 356 but also the overall medical care and related services. We cannot ignore the importance of 357 treatment, recovery and prevention in this pandemic. The patient experience is extremely 358 important in isolation centers to build patient confidence in paramedics and physicians. A better 359 experience will also contribute to reducing pain for patients. The factors affecting the pain level of patients are satisfaction with doctors and medicine, satisfaction with life, income adequacy, and fear. An improved isolation facility with quality of doctors and medicine can help to reduce the pain level of the patients.

363 It is important to maintain isolation facilities for patients by providing a comfortable environment to patients where they can recover and feel satisfied and perceive less pain. Improving the patient experience may improve the overall quality of hospitals and, as a result, hospitals will face fewer complaints. Being a developing country, income adequacy is also an important factor affecting pain and patient satisfaction. Satisfaction with medical care helps the individual to perceive less 368 pain.

369 Creating public isolation facilities and equipping them with the latest available facilities is a great 370 initiative, especially in developing countries where masses cannot afford these facilities at an out371 of-pocket expense. The focus on the provision of services can improve their experience and thus 372 patient satisfaction. However, patient satisfaction is not significantly different between the distinct 373 groups of the population. Improving overall facilities may help to increase the patient satisfaction 374 of patients. Reduction of fear through proper counseling and media awareness may help to bring 375 down the perceived pain of patients. Improving isolation experience will also help decrease 
376 negligence in other patients about their diseases and approach the hospitals for isolation, believing

377 that they are in trusted hands.

378

\section{References}

380

381

382

383

384

385

386

387

388

389

390

391

392

393

394

395

396

397

398

399

400

401

402

403

404

405

406

407

408

409

410

411

412

Abad C, Fearday A, and Safdar N. 2010. Adverse effects of isolation in hospitalised patients: a systematic review. Journal of Hospital Infection 76:97-102. DOI: 10.1016/j.jhin.2010.04.027

Ahorsu DK, Lin C-Y, Imani V, Saffari M, Griffiths MD, and Pakpour AH. 2020. The fear of COVID-19 scale: development and initial validation. International Journal of Mental Health and Addiction.

Amol Soin, M., Srinivas Vuppala, M., Gregory Surfield, M., Ricardo Buenaventura, M., Mark Malinowski, D., Rajaratnam, A., . . . Aarti Singla, M. (2020). Ohio response to COVID-19 and its impact on interventional pain management practices. Pain physician, 23, S439-S447.

Anthony Jnr, B. (2021). Implications of telehealth and digital care solutions during COVID-19 pandemic: a qualitative literature review. Informatics for Health and Social Care, $46(1), 68-83$.

Anthony Jnr, B. (2021). Integrating telemedicine to support digital health care for the management of COVID-19 pandemic. International Journal of Healthcare Management, 14(1): 280-289. doi: 10.1080/20479700.2020.1870354.

Asmundson, G. J., Vlaeyen, J. W. S., Vlaeyen, J. W., \& Crombez, G. (2004). Understanding and treating fear of pain: Oxford University Press, USA.

Baker P, Van der Meulen J, Lewsey J, and Gregg P. 2007. The role of pain and function in determining patient satisfaction after total knee replacement: data from the National Joint Registry for England and Wales. The Journal of bone and joint surgery British volume 89:893-900.

Bergefurt L, Kemperman A, van den Berg P, Borgers A, van der Waerden P, Oosterhuis G, and Hommel M. 2019. Loneliness and Life Satisfaction Explained by Public-Space Use and Mobility Patterns. International journal of environmental research and public health 16:4282. 10.3390/ijerph16214282

Bland, J. M., \& Altman, D. G. (1997). Statistics notes: Cronbach's alpha. British Medical Journal, 314(7080), 572.

Brooks SK, Webster RK, Smith LE, Woodland L, Wessely S, Greenberg N, and Rubin GJ. 2020. The psychological impact of quarantine and how to reduce it: rapid review of the evidence. The Lancet.

Centre for Disease Control and Protection. 2020. Quarantine and isolation. Available at https://www.cdc.gov/quarantine/index.html (accessed April 2021) 
413

414

415

416

417

418

419

420

421

422

423

424

425

426

427

428

429

430

431

432

433

434

435

436

437

438

439

440

441

442

443

444

445

446

447
Crombez G, Viane I, Eccleston C, Devulder J, and Goubert L. 2013. Attention to pain and fear of pain in patients with chronic pain. Journal of behavioral medicine 36:371-378.

Dzomeku V, Ba-Etilayoo A, Perekuu T, and Mantey R. 2013. In patient satisfaction with nursing care: a case study at kwame nkrumah university of science and technology hospital. International Journal of Research in Medical and Health Sciences 2:1924.

Giubilini A, Douglas T, Maslen H, and Savulescu J. 2018. Quarantine, isolation and the duty of easy rescue in public health. Developing world bioethics 18:182-189.

Huskisson EC. 1974. Measurement of pain. The Lancet 304:1127-1131.

Hwang T-J, Rabheru K, Peisah C, Reichman W, and Ikeda M. 2020. Loneliness and social isolation during the COVID-19 pandemic. International Psychogeriatrics 32:12171220. 10.1017/S1041610220000988

Karaca A, and Durna Z. 2019. Patient satisfaction with the quality of nursing care. Nursing Open 6:535-545. DOI: 10.1002/nop2.237

Keefe FJ, Abernethy AP, and C. Campbell L. 2005. Psychological approaches to understanding and treating disease-related pain. Annu Rev Psychol 56:601-630.

Koyama T, McHaffie JG, Laurienti PJ, and Coghill RC. 2005. The subjective experience of pain: where expectations become reality. Proceedings of the National Academy of Sciences 102:12950-12955.

Lochman JE. 1983. Factors related to patients' satisfaction with their medical care. Journal of Community Health 9:91-109. DOI: 10.1007/BF01349873

Lu C-w, Liu X-f, and Jia Z-f. 2020. 2019-nCoV transmission through the ocular surface must not be ignored. Lancet (London, England) 395:e39.

Markfelder, T., \& Pauli, P. (2020). Fear of pain and pain intensity: Meta-analysis and systematic review. Psychological Bulletin, 146(5), 411.

Mattioli AV, Puviani MB, Nasi M, and Farinetti A. 2020. COVID-19 pandemic: the effects of quarantine on cardiovascular risk. European Journal of Clinical Nutrition:1-4.

Maunder R, Hunter J, Vincent L, Bennett J, Peladeau N, Leszcz M, Sadavoy J, Verhaeghe LM, Steinberg R, and Mazzulli T. 2003. The immediate psychological and occupational impact of the 2003 SARS outbreak in a teaching hospital. Canadian Medical Association Journal 168:1245-1251.

McCarthy S, and Habib MA. 2018. Investigation of life satisfaction, travel, built environment and attitudes. Journal of Transport \& Health 11:15-24.

Ministry of National Institute of Health. 2020. Islamabad, Pakistan. Available at Retrieved from: http://covid.gov.pk/ (accessed Jan 2021) 
448

449

450

451

452

453

454

455

456

457

458

459

460

461

462

463

464

465

466

467

468

469

470

471

472

473

474

475

476

477

478

479
Raja, S. N., Carr, D. B., Cohen, M., Finnerup, N. B., Flor, H., Gibson, S., . . Sluka, K. A. (2020). The revised International Association for the Study of Pain definition of pain: concepts, challenges, and compromises. Pain, 161(9), 1976-1982.

Rees J, Davies HR, Birchall C, and Price J. 2000. Psychological effects of source isolation nursing (2): patient satisfaction. Nursing Standard (through 2013) 14:32.

Scher C, Meador L, Van Cleave JH, and Reid MC. 2018. Moving beyond pain as the fifth vital sign and patient satisfaction scores to improve pain care in the 21st century. Pain Management Nursing 19:125-129.

Song, X. J., Xiong, D. L., Wang, Z. Y., Yang, D., Zhou, L., \& Li, R. C. (2020). Pain management during the COVID-19 pandemic in China: Lessons learned. Pain Medicine, 21(7), 1319-1323.

Sprang G, and Silman M. 2013. Posttraumatic stress disorder in parents and youth after health-related disasters. Disaster medicine and public health preparedness 7:105110.

Stelfox HT, Bates DW, and Redelmeier DA. 2004. Quality of Care and Satisfaction Among Patients Isolated for Infection Control-Reply. JAMA 291:420-422. 10.1001/jama.291.4.421-b

Taber, K. S. (2018). The use of Cronbach's alpha when developing and reporting research instruments in science education. Research in Science Education, 48(6), 12731296.

Tang, F., Liang, J., Zhang, H., Kelifa, M. M., He, Q., \& Wang, P. (2020). COVID-19 related depression and anxiety among quarantined respondents. Psychology \& Health, 115.

Tongco, M. D. C. (2007). Purposive sampling as a tool for informant selection. Ethnobotany Research and applications, 5, 147-158.

World Health Organization. 2020. Statement on the second meeting of the International Health Regulations (2005) Emergency Committee regarding the outbreak of novel coronavirus (2019-nCoV).

Wudu, M. A. (2021). Predictors of Adult Patient Satisfaction with Inpatient Nursing Care in Public Hospitals of Eastern Amhara Region, Northeastern Ethiopia, 2020. Patient preference and adherence, 15, 177. 
Table $\mathbf{1}$ (on next page)

Demographics of the respondents 
1 Table 1. Demographics of the respondents

\begin{tabular}{llc}
\hline Variables & Categories & Frequency \\
\hline Age & Mean=38 & 88 \\
& Standard & \\
House possession & deviation= & \\
& Own & 52 \\
Head of Family & Rent & 40 \\
& Other & 8 \\
Feel Happy Before Pandemic & Yes & 53 \\
& No & 47 \\
& Not very happy & 16 \\
& Not happy & 12 \\
& Neutral & 17 \\
& Happy & 32 \\
Education & Very Happy & 23 \\
& Strongly Disagree & 2 \\
& Primary & 12 \\
& Secondary & 4 \\
& High School & 14 \\
& College & 15 \\
Employment Status & Graduate & 31 \\
& Post Graduate & 21 \\
& Full time & 62 \\
& Part time & 5 \\
& Unemployed & 21 \\
& Full time student & 4 \\
& Retired & 8 \\
\hline & &
\end{tabular}

2 


\section{Table 2 (on next page)}

Analysis of variance estimating the difference in patient satisfaction between categories of demographic variables 
1 Table 2. Analysis of variance estimating the difference in patient satisfaction between 2 categories of demographic variables

\begin{tabular}{|c|c|c|c|c|}
\hline & $\mathrm{N}$ & Mean (SD) & $\mathrm{F}$ & P-value \\
\hline Marital Status & & & 1.379 & 0.254 \\
\hline 1. Unmarried & 27 & $2.872(0.931)$ & & \\
\hline 2. Married & 68 & $1.500(1.211)$ & & \\
\hline 3. Widow & 2 & $2.071(0.707)$ & & \\
\hline 4. Divorced & 2 & $2.857(1.111)$ & & \\
\hline Education level & & & 1.673 & 0.149 \\
\hline 1. Primary & 12 & $2.214(1.336)$ & & \\
\hline 2. Secondary & 4 & $2.320(0.513)$ & & \\
\hline 3. High School & 15 & $2.666(1.072)$ & & \\
\hline 4. College & 15 & 3.019 (1.292) & & \\
\hline 5. Graduate & 27 & $3.218(1.084)$ & & \\
\hline 6. Postgraduate & 22 & $2.871(1.020)$ & & \\
\hline Gender & & & 0.119 & 0.730 \\
\hline 1. Male & 48 & $2.816(1.023)$ & & \\
\hline 2. Female & 51 & $2.896(1.125)$ & & \\
\hline
\end{tabular}

3 
Table 3 (on next page)

Ordered logistic regression showing effect of different factors affecting pain level 
1 Table 3: Ordered logistic regression showing effect of different factors affecting pain level

\begin{tabular}{|c|c|c|}
\hline \multirow[b]{2}{*}{ VARIABLES } & \multicolumn{2}{|c|}{ Odds ratio } \\
\hline & Model 1 & Model 2 \\
\hline \multicolumn{3}{|l|}{ Fear } \\
\hline Strongly agree & $\begin{array}{c}12.64 \\
(0.389-410.1)\end{array}$ & $\begin{array}{c}2.686 \\
(0.115-62.79)\end{array}$ \\
\hline Agree & $\begin{array}{c}10.25 \\
(0.430-244.3)\end{array}$ & $\begin{array}{c}5.870 \\
(0.327-105.3)\end{array}$ \\
\hline Neutral & $\begin{array}{c}39.55 * * \\
(1.792-872.7)\end{array}$ & $\begin{array}{c}66.72 * * * \\
(3.196-1,393)\end{array}$ \\
\hline Disagree & $\begin{array}{c}0.186 \\
(0.00869-3.975)\end{array}$ & $\begin{array}{c}0.387 \\
(0.0213-7.009)\end{array}$ \\
\hline \multicolumn{3}{|l|}{$\begin{array}{l}\text { Base category: strongly } \\
\text { disagree }\end{array}$} \\
\hline Age & $\begin{array}{c}0.940 * * \\
(0.889-0.994)\end{array}$ & $\begin{array}{c}0.963 * * \\
(0.915-1.014)\end{array}$ \\
\hline \multicolumn{3}{|l|}{$\begin{array}{l}\text { Satisfaction with } \\
\text { medicine during isolation }\end{array}$} \\
\hline Dissatisfied & $\begin{array}{c}0.01000^{* *} \\
(0.000108-0.929)\end{array}$ & $\begin{array}{c}0.131 * \\
(0.0150-1.149)\end{array}$ \\
\hline $\begin{array}{l}\text { Neither satisfied nor } \\
\text { dissatisfied }\end{array}$ & $\begin{array}{c}0.00389 * * \\
(4.47 \mathrm{e}-05-0.338)\end{array}$ & $\begin{array}{c}0.0476 * * \\
(0.00386-0.587)\end{array}$ \\
\hline Satisfied & $\begin{array}{c}0.0230 * * \\
(0.00117-0.452)\end{array}$ & $\begin{array}{c}0.0734 * * \\
(0.00856-0.630)\end{array}$ \\
\hline Very satisfied & $\begin{array}{c}0.0541 * * \\
(0.00427-0.686)\end{array}$ & $\begin{array}{c}0.193 \\
(0.0250-1.494)\end{array}$ \\
\hline $\begin{array}{l}\text { Base category: Very } \\
\text { dissatisfied } \\
\text { Sufficiency of income }\end{array}$ & & \\
\hline Can meet necessities & $\begin{array}{c}0.155^{* *} \\
(0.0324-0.740)\end{array}$ & $\begin{array}{c}0.376^{* *} \\
(0.0876-1.616)\end{array}$ \\
\hline Can afford somethings & $\begin{array}{c}0.499 \\
(0.109-2.283)\end{array}$ & $\begin{array}{c}0.370 \\
(0.0885-1.545)\end{array}$ \\
\hline Can afford everything & $\begin{array}{c}5.131 \\
(0.547-48.13)\end{array}$ & $\begin{array}{c}1.645 \\
(0.292-9.276)\end{array}$ \\
\hline $\begin{array}{l}\text { Afford everything and } \\
\text { still save money }\end{array}$ & 2.040 & $4.389 \mathrm{e}+11$ \\
\hline $\begin{array}{l}\text { Base category: Not at all } \\
\text { adequate }\end{array}$ & $(0.01-0.02)$ & $(0.01-0.02)$ \\
\hline $\begin{array}{l}\text { Satisfaction with life } \\
\text { Disagree }\end{array}$ & $122.0 * * *$ & $39.77 * * *$ \\
\hline
\end{tabular}


Neutral

Agree

Strongly agree

Base category:

Strongly disagree

Satisfaction with the doctors

Disagree

Neutral

Agree

Strongly agree

Base category: Strongly

disagree

Constant cut 1

Constant cut2

Constant cut 3

Constant cut 4

Pseudo R square

F statistics

F statistics p-value

AIC

BIC

Observations

$$
(6.887-2,162)
$$

$744.9 * * *$

(19.59 - 28,329)

$61.06 * *$

(2.556-1,458)

12.63

(0.0634 - 2,514)
$(2.846-555.7)$

$47.88 * * *$

(3.103 - 738.7)

8.329

(0.614 - 113.0)

5.612

(0.0641 - 491.4)

$$
8.997
$$

$(0.233-348.1)$

$0.0315^{*}$

$(0.000656-1.515)$

0.806

(0.0933 - 6.967)

0.97

(0.1 - 1)
0.141

$(0.00226-8.758)$

2.515

$(0.0458-138.2)$

24.55

$(0.420-1,435)$

$320.1 * * *$

$(4.730-21,668)$

0.323

86.323

0.000

230.279

292.213
0.269

71.90

0.000

238.693

293.194

88

2 Dependent variable: Pain level

$3 *$ p-value $<0.1, * *$ p-value $<0.05, * * *$ p-value $<0.01$

4 


\section{Table 4 (on next page)}

Summary of Construct's R square, Beta Coefficient, t-value and Significance level

Summary of Construct's R square, Beta Coefficient, t-value and Significance level 
1 Table 4: Summary of Construct's R square, Beta Coefficient, t-value and Significance level

\begin{tabular}{|c|c|c|c|}
\hline Hypothesis & $\begin{array}{l}\text { Path/Beta } \\
\text { Coefficient }\end{array}$ & t-value & p-value \\
\hline Age & -0.222 & 2.231 & $0.026^{* *}$ \\
\hline Number of dependents & 0.024 & 0.236 & 0.813 \\
\hline Education & 0.276 & 2.961 & $0.003 * * *$ \\
\hline Household size & 0.097 & 0.820 & 0.413 \\
\hline $\begin{array}{l}\text { House ownership (own } \\
\text { house) }\end{array}$ & -0.404 & 4.563 & $0.000 * * *$ \\
\hline Base category: rented house & & & \\
\hline Income adequacy & -0.237 & 2.299 & $0.022 * *$ \\
\hline Marital Status (married) & -0.084 & 1.005 & 0.315 \\
\hline (Base category: unmarried) & & & \\
\hline Negligence & 0.201 & 1.975 & $0.049 * *$ \\
\hline Pain Level & 0.348 & 3.420 & $0.001 * * *$ \\
\hline
\end{tabular}

2 Dependent variable: Patient satisfaction

$3 *$ p-value $<0.1, * *$ p-value $<0.05, * * *$ p-value $<0.01$ 